\title{
Mechanism of genotoxicity induced by targeted cytoplasmic irradiation
}

\author{
M Hong ${ }^{1,2}$, A Xu ${ }^{1,3}$, H Zhou', L Wu ${ }^{3}$, G Randers-Pehrson', RM Santella ${ }^{4}, Z$ Yu$^{3}$ and TK Hei ${ }^{*, 1,4}$ \\ 'Center for Radiological Research, Department of Radiation Oncology, College of Physicians and Surgeons, Columbia University Medical Center, 630 \\ West 168th Street, New York, NY 10032, USA; ${ }^{2}$ Department of Biochemistry and Molecular Biology, College of Life Science, South China Agricultural \\ University, Guangzhou, China; ${ }^{3}$ Key laboratory of Ion Beam Bioengineering, Institute of Plasma Physics, Chinese Academy of Science, Hefei, China; \\ ${ }^{4}$ Department of Environmental Health Sciences, Mailman School of Public Health, Columbia University, New York, NY, USA
}

BACKGROUND: Direct damage to DNA is generally accepted as the main initiator of mutation and cancer induced by environmental carcinogens or ionising radiation. However, there is accumulating evidence suggesting that extracellular/extranuclear targets may also have a key role in mediating the genotoxic effects of ionising radiation. As the possibility of a particle traversal through the cytoplasm is much higher than through the nuclei in environmental radiation exposure, the contribution to genotoxic damage from cytoplasmic irradiation should not be ignored in radiation risk estimation. Although targeted cytoplasmic irradiation has been shown to induce mutations in mammalian cells, the precise mechanism(s) underlying the mutagenic process is largely unknown.

METHODS: A microbeam that can target the cytoplasm of cells with high precision was used to study mechanisms involved in mediating the genotoxic effects in irradiated human-hamster hybrid $\left(A_{L}\right)$ cells.

RESULTS: Targeted cytoplasmic irradiation induces oxidative DNA damages and reactive nitrogen species (RNS) in $A_{L}$ cells. Lipid peroxidation, as determined by the induction of 4-hydroxynonenal was enhanced in irradiated cells, which could be suppressed by butylated hydroxyl toluene treatment. Moreover, cytoplasmic irradiation of $A_{L}$ cells increased expression of cyclooxygenase- 2 (COX-2) and activation of extracellular signal-related kinase (ERK) pathway.

CONCLUSION: We herein proposed a possible signalling pathway involving reactive oxygen/nitrogen species and COX-2 in the cytoplasmic irradiation-induced genotoxicity effect.

British Journal of Cancer (2010) I 03, I263-1268. doi:I0.1038/sj.bjc.6605888 www.bjcancer.com

Published online 14 September 2010

(c) 2010 Cancer Research UK

Keywords: cytoplasmic irradiation; genotoxicity; reactive oxygen/nitrogen species; 4-hydroxynonenal; cyclooxygenase-2

Direct damage to DNA caused by environmental carcinogens and ionising radiation has been considered as a significant initiator of deleterious effects, such as mutation and cancer. However, recent reports suggest that extracellular/extranuclear targets may have a role in mediating the genotoxic effects of radiation (Little, 2000; Morgan, 2003). In our previous studies, we have shown that irradiation of the cytoplasm produces gene mutations in the nucleus of the hit cells and that this process is mediated by free radicals (Wu et al, 1999).

One of the most abundant oxidative lesions caused by reactive oxygen species (ROS) in DNA is 8-hydroxydeoxyguanosine (8-OHdG), a potential mutagenic lesion (Gajewski et al, 1990). Although evidence has indicated that X-ray, $\gamma$-ray, and ultraviolet radiation are able to induce the formation of $8-O H d G$ in purified DNA and various cultured cells (Kamiya et al, 1992; Takeuchi and Morimoto, 1994), direct proof of oxidative DNA damages induced by extranuclear events including targeted cytoplasmic irradiation is lacking. Another type of bioactive molecules, the reactive nitrogen species (RNS) such as peroxynitrite anions $\left(\mathrm{ONOO}^{-}\right)$, are formed through interaction of

*Correspondence: Professor TK Hei; E-mail: tkhI@columbia.edu Received I June 20 I0; revised 9 August 20 I0; accepted 10 August 20 I0; published online 14 September 2010 nitric oxide (NO) with superoxide anions. Reactive nitrogen species have been shown to be potent inducers of apoptosis and necrosis. They may also inhibit DNA repair mechanisms leading to mutation and carcinogenesis (Burney et al, 1997). Although there is evidence suggesting a close association between RNS and cellular response induced by irradiation (Hirst and Robson, 2007), the role of RNS in the mutagenic effect of $\alpha$-particle irradiation is not clear.

The presence of oxidants as well as free radicals in cellular systems can also adversely alter lipids, proteins, and DNA (Devasagayam et al, 2004). Decomposition of the lipid peroxyl radicals or the primary free radical intermediate of lipid peroxidation lead to the generation of reactive aldehydes such as 4-hydroxynonenal (4-HNE). 4-Hydroxynonenal has been implicated in a number of oxidative stress-related diseases, including atherosclerosis (Requena et al, 1996), neurodegenerative diseases (Floyd and Hensley, 2002), and fibrosis (Leonarduzzi et al, 1997). Moreover, there have been numerous studies indicating that 4-HNE can stimulate cellular proliferation (Dianzani et al, 1999), differentiation (Yang et al, 2003), and cytoprotective response (Dickinson et al, 2002; Zhang et al, 2005) through effects on multiple signalling pathways.

To investigate the underlying mechanisms involved in the mutagenicity of cytoplasmic irradiation, we used a charged particle microbeam developed at the Radiological Research Accelerator 
Facility of Columbia University, in which the cytoplasm of individual cells could be targeted and irradiated with defined

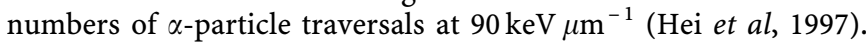
A sensitive mutagenic assay system using the human-hamster hybrid $A_{L}$ cells was used for the study. We show here that cytoplasmic irradiation induced the formation of $8-\mathrm{OHdG}$, and that inhibition of nitric oxide synthase with $N^{G}$-methyl-L-arginine (L-NMMA) could suppress the mutant fraction. As downstream products generated from free radicals and oxidants, we also detected significantly increased levels of 4-HNE, cycloxygenase-2 $(\mathrm{COX}-2)$, and the activation of extracellular signal-related kinase (ERK).

\section{MATERIALS AND METHODS}

\section{Cell culture}

The human-hamster hybrid $\mathrm{A}_{\mathrm{L}}$ cells that contain a standard set of Chinese hamster ovary-K1 chromosomes and a single copy of human chromosome 11 were used (Waldren et al, 1979). These cells were cultured in Ham's F12 medium supplemented with $8 \%$ heat inactivated fetal bovine serum (Atlanta Biological, Norcross, GA, USA), $2 \times 10^{-4} \mathrm{M}$ glycine, and $25 \mu \mathrm{g} \mathrm{ml}^{-1}$ gentamycin at $37^{\circ} \mathrm{C}$ in a humidified $5 \% \quad \mathrm{CO}_{2} / 95 \%$ air incubator and passaged as described (Wu et al, 1999). All the chemicals are from Sigma (St Louis, MO, USA) except where otherwise indicated.

\section{Exposure to $\alpha$-particles}

The layout and methods for the cytoplasmic irradiation using the microbeam have been described previously (Hei et al, 1997; $\mathrm{Wu}$ et al, 1999). For precision targeting of cellular cytoplasm, exponentially growing $A_{L}$ cells were plated at a density of 500-600 cells per microbeam dish $24 \mathrm{~h}$ before irradiation. An image analysis system was used to locate each cell and a precision beam was delivered to the cytoplasmic sites with an accuracy of $\pm 1 \mu \mathrm{m}$ as described. The cytoplasm of each cell was irradiated at each of two sites chosen to be $8 \mu \mathrm{m}$ from the ends of the major axis of each nucleus as described (Wu et al, 1999). Dose measurement and accuracy were determined using the detector mounted on the microscope lens.

\section{Treatment with dimethyl sulfoxide (DMSO)}

$\mathrm{A}_{\mathrm{L}}$ cells were treated with $8 \%$ DMSO $10 \mathrm{~min}$ before and $3 \mathrm{~min}$ after irradiation with eight $\alpha$-particles targeted through the cytoplasm. The dose of DMSO used was nontoxic and nonmutagenic under the conditions used in the study and as shown by others (Wu et al, 1999). After treatment, cells were fixed with 5\% acetic acid-ethanol at $-20^{\circ} \mathrm{C}$ for immunoperoxidase staining.

\section{Treatment with inhibitors}

$A_{L}$ cells were treated with the lipid peroxidation inhibitor, butylated hydroxyl toluene (BHT, $100 \mu \mathrm{M})$, the mitogen-activated protein (MAP) kinase cascade inhibitor PD98059 $(50 \mu \mathrm{M})$, L-NMMA or its inactive D-enantiomer, D-NMMA (both at $1 \mathrm{mM}$ from Molecular Probes, Eugene, OR, USA), or the COX-2 inhibitor NS-398 $(50 \mu \mathrm{M})$ before irradiation with eight $\alpha$-particles targeted through the cytoplasm. Medium containing the inhibitor was added back to the microbeam dish after irradiation. Cells were incubated for $4 \mathrm{~h}$ and fixed with $4 \%$ paraformaldehyde for immunocytochemistry analysis. For peroxynitrite detection, cells were incubated for $16 \mathrm{~h}$ before fixation and immunostaining. For the mutagenesis assay, cells were incubated overnight in medium containing inhibitors. The medium was removed just before the irradiation and then fresh medium with inhibitors was added back to the cells and they were grown for $16-18 \mathrm{~h}$ and then returned back to grow in medium without inhibitors.

\section{Immunoperoxidase staining for 8-OHdG}

Induction of $8-\mathrm{OHdG}$ in the nucleus of $\mathrm{A}_{\mathrm{L}}$ cells irradiated with $\alpha$-particles through the cytoplasm was quantified using the monoclonal antibody 1 F7 specific for $8-\mathrm{OHdG}$ coupled with immunoperoxidase staining and image analysis software as described (Hei et al, 1998; Xu et al, 1999). A Cell Analysis System CAS 200 microscope and a Cell Measurement Software package (Becton Dickinson, San Jose, CA, USA) were used to quantify the relative staining intensity from 50 randomly selected cells per dish. A total of 150-200 cells were measured from either the control or the irradiated groups. Data presented are the average absorbance of three experiments multiplied by 1000 .

\section{Immunostaining}

At $4 \mathrm{~h}$ after irradiation, $\mathrm{A}_{\mathrm{L}}$ cells were washed three times with PBS, fixed for $15 \mathrm{~min}$ at room temperature in $4 \%(\mathrm{w} / \mathrm{v})$ paraformaldehyde in PBS and then washed in PBS. The fixed cells were permeabilised with $0.1 \%$ Triton $\mathrm{X}-100$ for $10 \mathrm{~min}$ and washed three times with PBS. The cells were incubated for $1 \mathrm{~h}$ at room temperature in PBS containing 5\% (v/v) goat serum and then incubated for $1 \mathrm{~h}$ in the same medium containing anti-4-HNE $(10 \mu \mathrm{g} / \mathrm{ml}, \mathrm{R} \& \mathrm{D}$ Systems, Inc, Minneapolis, MN, USA), COX-2 ( $1: 100$, Cayman Chemical, Ann Arbor, MI, USA), p-ERK (1:100, Cell Signaling Technology, Inc, Danvers, MA, USA) or nitrotyrosine antibody ( $1: 100$, Molecular Probes, Carlsbad, CA, USA) at room temperature. Staining for nitrotyrosine was used as a surrogate marker for peroxynitrite anions. The cells were washed and bound primary antibodies were detected by the reaction with Alexa Fluor 488 goat anti-mouse or Alexa Fluor 594 goat antirabbit IgG antibody diluted $1: 200$, for $1 \mathrm{~h}$. Cells were thoroughly washed and the polypropylene layer was cut out and placed on a glass slide. A cover glass was placed on top of the polypropylene layer and mounted using VECTASHIELD HardSet Mounting Medium (Vector laboratories, Burlingame, CA, USA). Samples were examined using a Nikon $\mathrm{C} 1$ confocal fluorescence microscope (Nikon, Melville, NY, USA). Semiquantitative estimation of fluorescence intensity was obtained using the composite images generated by Image J software (NIH, Bethesda, MD, USA). Relative staining intensity from 100 randomly selected cells was analysed per dish. A total of 300-400 cells were measured from either the control or the irradiated groups.

\section{Mutation assay}

After irradiation, cells were trypsinised and plated into a T-25 flask and cultured for 7-9 days. To determine mutant yield, $5 \times 10^{4}$ cells were plated into each of six $60 \mathrm{~mm}$ dishes in a total of $2 \mathrm{ml}$ growth medium as described (Hei et al, 1998). The cells were incubated for $2 \mathrm{~h}$ to allow cell attachment. Then 3\% CD59 antiserum and 1.6\% freshly thawed complement (v/v) were added to each dish. The cultures were further incubated for 7-10 days before being fixed, stained, and scored for the number of $\mathrm{CD} 59^{-}$mutants. The cultures from each treatment were tested for mutant yield for two consecutive weeks to ensure the full expression of the mutation. Mutant fractions were calculated as the number of surviving colonies divided by the total number of cells plated after correction for non-specific killing because of complement alone.

\section{Statistics}

Statistical analysis was carried out using Student's $t$-test. Differences between means are regarded as significant if $P<0.05$. 


\section{RESULTS}

\section{Induction of oxidative stress in cytoplasmic irradiation}

To determine whether cytoplasmic irradiation can induce oxidative DNA damage, we used immunoperoxidase staining to detect 8-OHdG levels after irradiating with eight $\alpha$-particles through the cytoplasm. A representative immunoperoxidase staining for 8-OHdG is shown in Figure 1A. 8-Hydroxydeoxyguanosine was localised mainly in the nucleus of both control and irradiated cells. Although a faint, background staining was evident in the control cultures, cytoplasmic irradiation resulted in a significant induction of 8-OHdG in $A_{L}$ cells. Quantification of staining in 200 randomly selected cells indicated that there was a 2.7 -fold increase in the relative staining intensity of $8-\mathrm{OHdG}$ in cells irradiated with eight $\alpha$-particles through the cytoplasm when compared with the non-irradiated cells. Concurrent treatment with the free radical scavenger DMSO suppressed formation of 8 -OHdG and reduced the staining intensity close to background levels (Figure $1 \mathrm{~B}, P<0.05)$. Furthermore, cells that were cytoplasmically traversed by $\alpha$-particles also exhibited higher fluorescence intensity in chloromethyl dichlorodihydrofluorescein diacetate (a cell-permeable fluorescent probe), for enhanced level of intracellular ROS (data not shown).

To evaluate the involvement of RNS in cytoplasmic irradiation, an antibody specific for nitrotyrosine was used as a surrogate marker for peroxynitrite anions to evaluate RNS generation. We detected approximately a two-fold increase in the level of peroxynitrite anion induction in cytoplasmically irradiated cells. The presence of L-NMMA, an inhibitor of nitric oxide synthase, suppressed peroxynitrite levels to control levels (Figure 1C). In addition to overall changes in fluorescence intensity, it was clear that the fluorescence signal in irradiated cells were localised both in nuclei and cytoplasm (Figure $1 \mathrm{C}$ ). $\mathrm{A}_{\mathrm{L}}$ cells pretreated with L-NMMA and irradiated showed detectable staining in the cytoplasm, but to a much less extent (50\% less). When we pretreated $A_{L}$ cells with L-NMMA, the treatment significantly reduced mutation yield by approximately three-fold (Figure 1D, $P<0.05)$. On the other hand, pretreatment of $A_{L}$ cells with an equivalent dose of the inactive enantiomer, D-NMMA, had no effect on the induction of mutations. These results indicate that RNS are also involved in the induction of mutations as a result of cytoplasmic irradiation.

\section{Cytoplasmic irradiation induces lipid peroxidation}

The presence of free radicals and oxidants often results in lipid peroxidation. As the major $\alpha, \beta$-unsaturated aldehydes derived
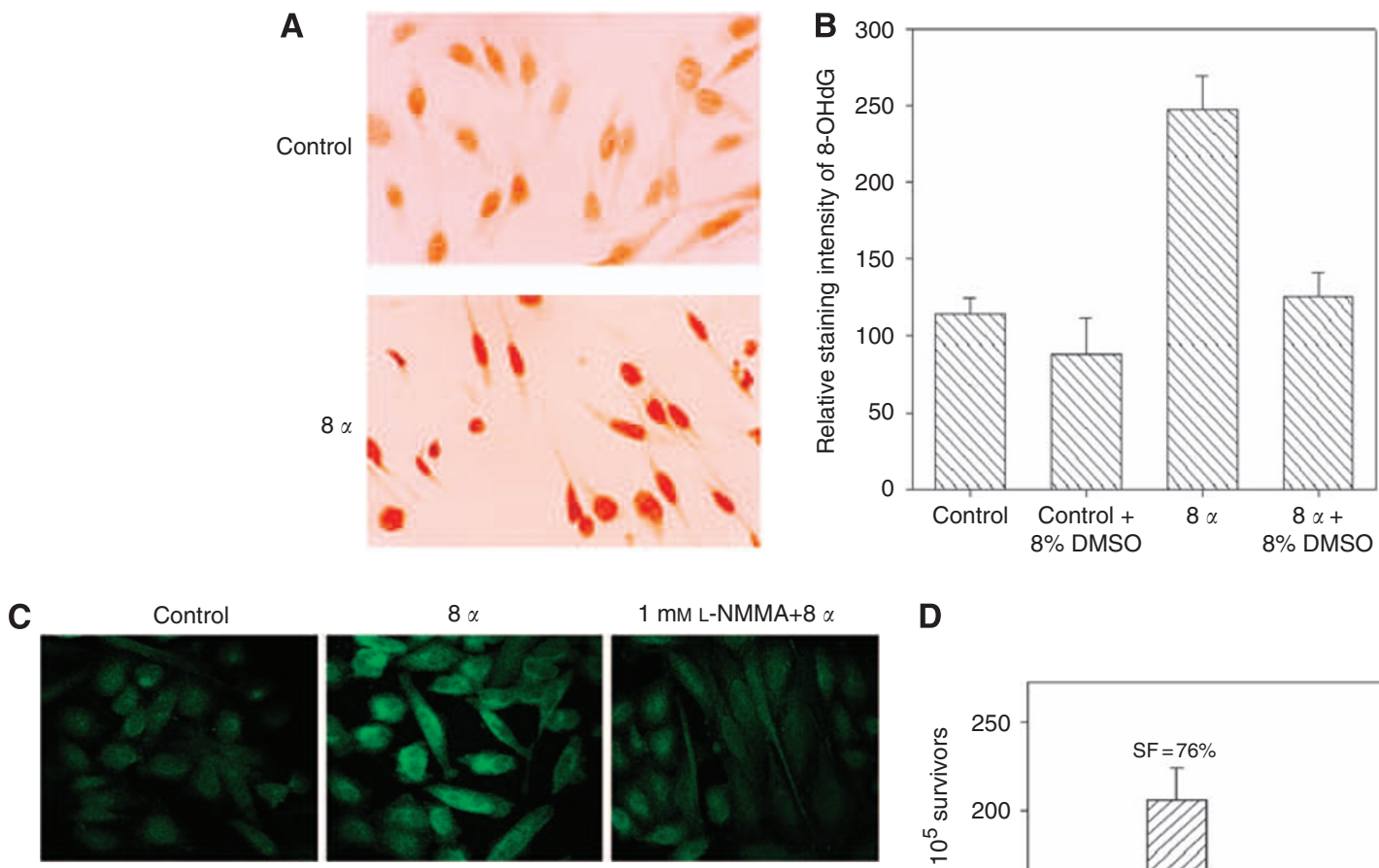

D
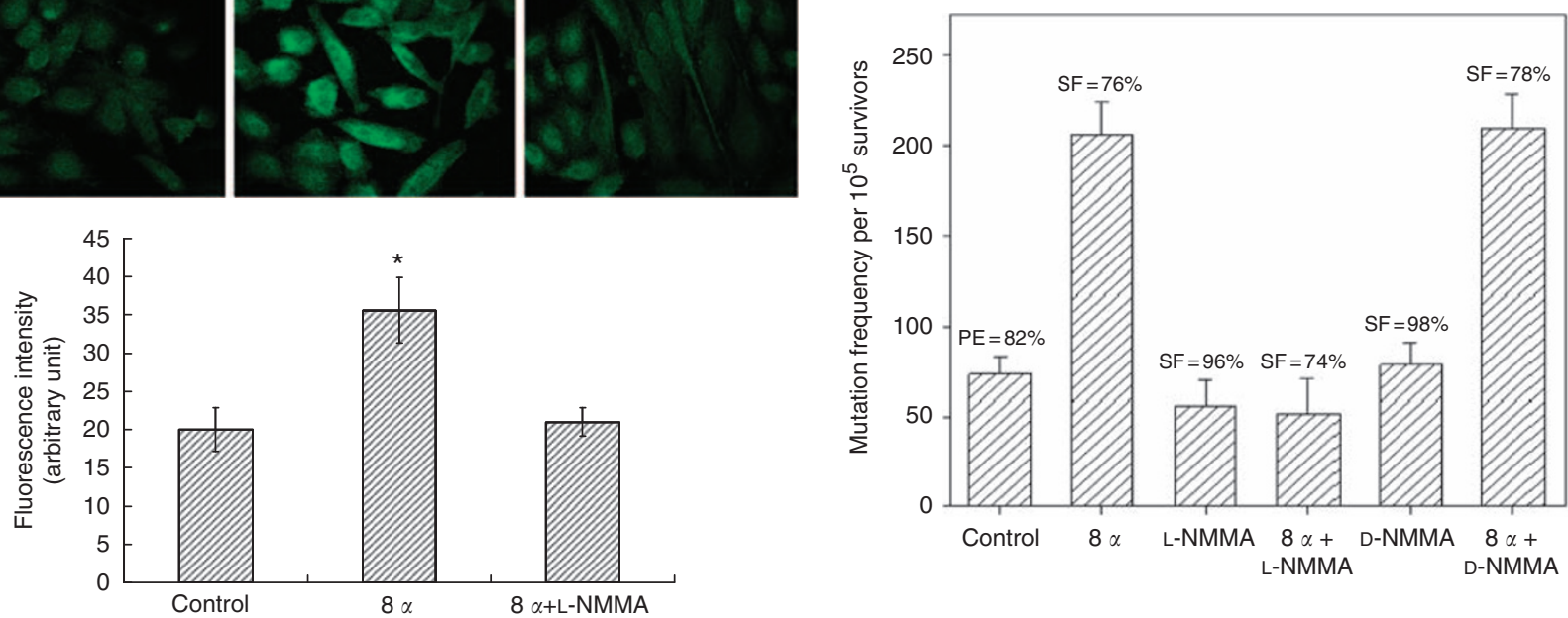

Figure I Induced ROS and RNS in cytoplasmic-irradiated $A_{L}$ cells. (A) Immunoperoxidase staining for 8-OHdG in $A_{L}$ cells. (B) Effect of DMSO on the induction of 8-OHdG in $A_{L}$ cells irradiated with eight $\alpha$-particles $(8 \alpha)$ through the cytoplasm. $(\mathbf{C})$ Nitrotyrosine fluorescent signals in $A_{L}$ cells after irradiation with 0 (control) or eight $\alpha$-particles. (D) Effect of L-NMMA or D-NMMA on the mutagenic potential of cytoplasmic irradiation at the CD59 locus of $A_{L}$ cells. Data averaged from three independent experiments. Bars indicate \pm s.e. of sample means (asterisk indicated $P<0.05$ ). $P E=$ plating efficiency; $S F=$ surviving fraction. 

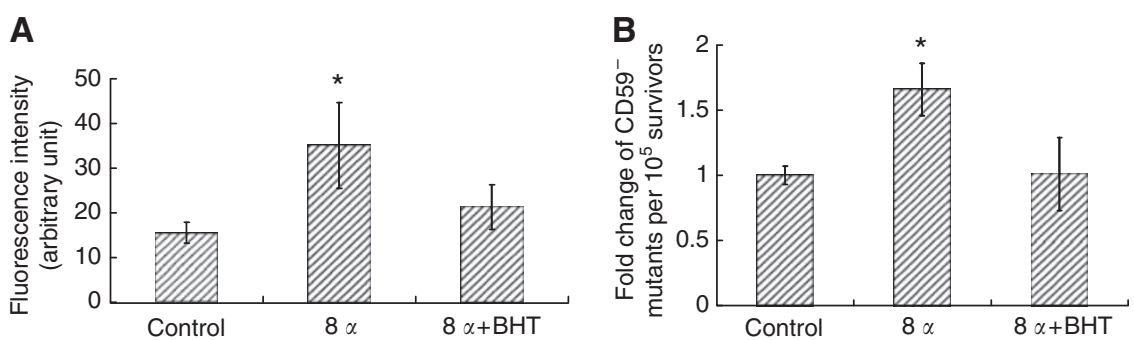

Figure 2 Lipid peroxidation in cytoplasmic-irradiated $A_{L}$ cells. $(\mathbf{A})$ Relative fluorescence intensity of 4-HNE in $A_{L}$ cells after irradiation with 0 (control) or eight $\alpha$-particle $(8 \alpha)$. (B) Effect of BHT on the mutagenic potential of cytoplasmic irradiation at the CD59 locus of $A_{L}$ cells. Data were averaged from three independent experiments. Bars indicate \pm s.e. of sample means (asterisk indicated $P<0.05$ )

from lipid peroxidation, 4-HNE is considered a biomarker of oxidative stress (Poli et al, 1987; Esterbauer et al, 1991) and has been shown to stimulate cellular proliferation (Dianzani et al, 1999), differentiation (Yang et al, 2003), and cytoprotective responses (Dickinson et al, 2002; Zhang et al, 2005) through various signalling pathways. Our next logical step was to analyse the lipid peroxidation level in irradiated cells. As indicated in Figure $2 \mathrm{~A}$, cells irradiated with eight $\alpha$-particles through the cytoplasm showed a significantly higher level of 4-HNE compared with the control, non-irradiated cells $(P<0.05)$. Moreover, pre-treating the cells with BHT, a well known lipid peroxidation chain blocker, suppressed the induction of lipid peroxidation.

To further evaluate the involvement of lipid peroxidation in cytoplasmic irradiation, we compared the CD59 ${ }^{-}$mutant yield in $A_{L}$ cells with or without pre-treatment with BHT. As shown in Figure $2 B, A_{L}$ cells irradiated with eight $\alpha$-particles through the cytoplasm showed approximately 1.8 -fold higher mutant yield as compared with control, non-irradiated cells, which is consistent with our previous report (Wu et al, 1999). However, when $A_{L}$ cells were pre-treated with $100 \mu \mathrm{M}$ of $\mathrm{BHT}$, the $\mathrm{CD} 59^{-}$mutation fraction was reduced back to a level that was compatible with the nonirradiated control, suggesting a link between lipid peroxidation and the mutagenic effect of cytoplasmic irradiation.

\section{Cyclooxygenase- 2 is induced in cytoplasmic-irradiated cells}

Cyclooxygenases (COXs) are a group of enzymes that catalyse the conversion of arachidonic acid into eicosanoids. Cyclooxygenase- 2 is an inducible isoform of COX and is responsible for the production of high levels of prostaglandin during tissue inflammation and other immune responses. It has been demonstrated that in foamy macrophages within human atheromatous lesions, COX-2 expression was associated with accumulation of lipid peroxidation product 4-HNE, suggesting an inducer function of 4-HNE on COX-2 in this system (Kumagai et al, 2004). To evaluate whether there is a similar relationship between lipid peroxidation and COX-2 in our cytoplasmic irradiation system, we measured the COX-2 expression in $A_{L}$ cells by immunostaining. It was found that COX-2 was significantly up-regulated after cytoplasmic irradiation. Furthermore, cells pre-treated with BHT partially suppressed COX-2 expression in irradiated cells (Figure 3A). Overnight treatment with $50 \mu \mathrm{m}$ of COX-2 inhibitor NS-398 before the irradiation significantly reduced the $\mathrm{CD} 59^{-}$mutant yield to basal levels, thus providing further support of COX-2 involvement in cytoplasmic irradiation-induced mutagenesis (Figure 3B).

\section{Activation of ERK signalling pathway in cellular response to cytoplasmic irradiation}

The MAPK pathways are responsible for the various growth factor-mediated cellular events such as proliferation, senescence,
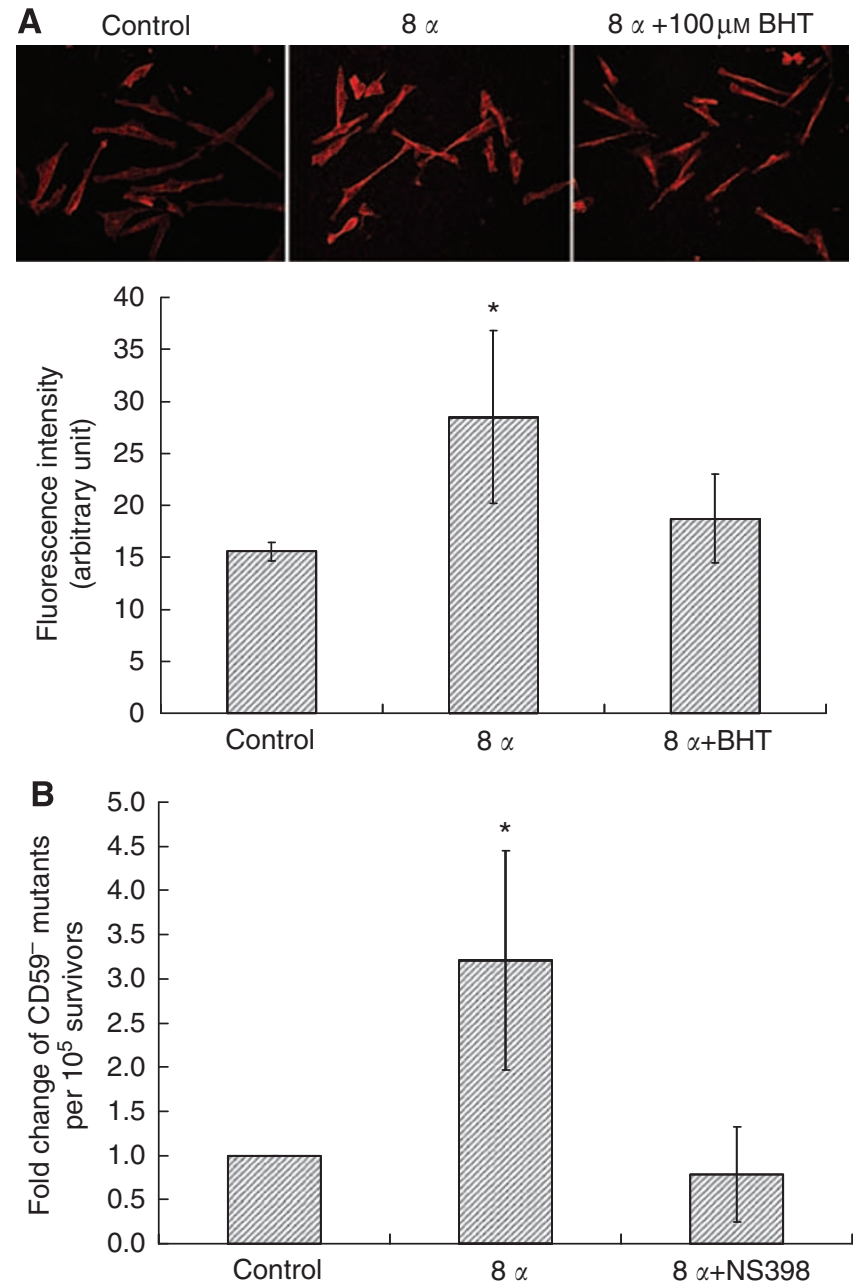

Figure 3 Cyclooxygenase-2 expression in cytoplasmic-irradiated $A_{\perp}$ cells, (A) Cyclooxygenase-2 fluorescent signal in $A_{L}$ cells after irradiation with 0 (control) or eight $\alpha$-particle ( $8 \alpha$ ) through the cytoplasm with or without co-treatment with $100 \mu \mathrm{M}$ BHT. (B) Effect of NS-398 on the mutagenic potential of cytoplasmic irradiation at the CD59 locus of $A_{L}$ cells. Data were averaged from three independent experiments. Bars indicate \pm s.e. of sample means (asterisk indicated $P<0.05$ ).

differentiation, and apoptosis. Numerous studies have shown that exposure of cells to ionising radiation as well as other toxic stresses can induce simultaneous compensatory activation of different MAPK pathways (Dent et al, 2003). There is evidence that 4-HNE can act as an inducer for COX-2, possibly through MAPK pathways (Kumagai et al, 2004). As shown in Figure 4A, cells irradiated with 

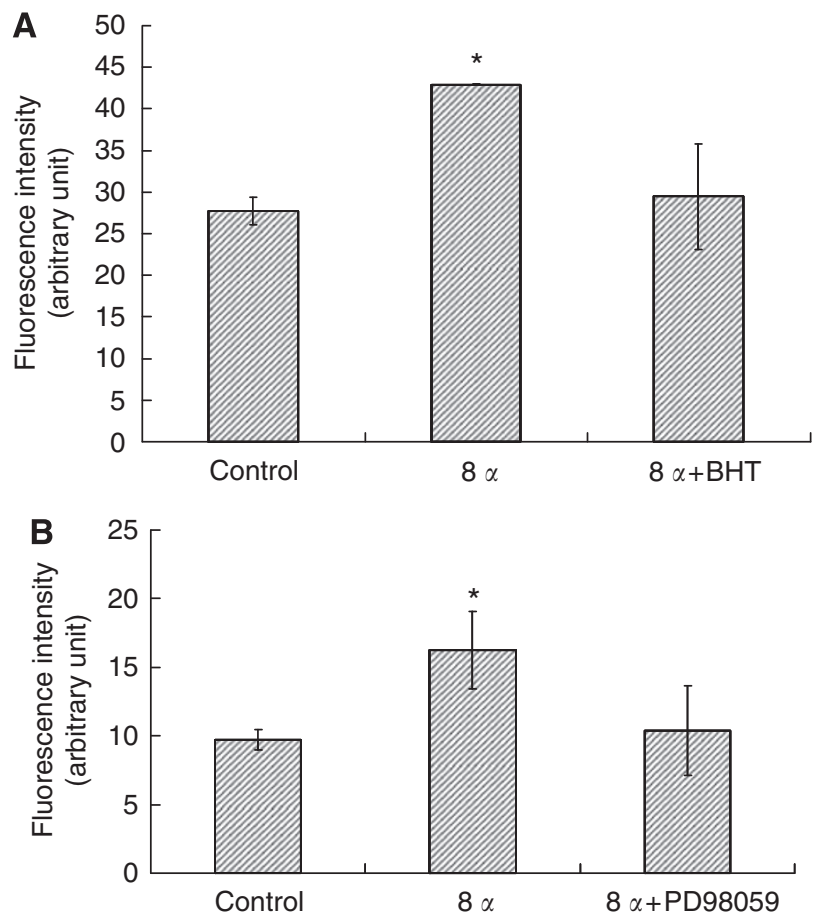

Figure 4 Extracellular signal-related kinase (ERK) activity in cytoplasmicirradiated $A_{L}$ cells. (A) Relative fluorescence intensity of $p$-ERK in $A_{L}$ cells with 0 (control) or after irradiation with eight $\alpha$-particles $(8 \alpha)$ through cytoplasm with or without I00 $\mu \mathrm{M}$ BHT treatment. (B) Relative fluorescence intensity of COX-2 in $A_{L}$ cells after irradiated with 0 (control) or eight $\alpha$-particles through the cytoplasm with or without treatment with $50 \mu \mathrm{M}$ PD98059, a specific inhibitor of the MAPK ERK (MEK). Data were averaged from three independent experiments. Bars indicate \pm s.e. of sample means (asterisk indicated $P<0.05)$.

eight $\alpha$-particles had a higher level of phospho-ERK when compared with that of the control, non-irradiated cells, suggesting that ERK is activated after cytoplasmic irradiation. Treatment of cells with BHT before irradiation reduced phospho-ERK to control levels, indicating that lipid peroxidation may act as an upstream activator of the ERK signalling pathway. If activation of ERK is critical in mediating the irradiation-induced up-regulation of COX-2, it should be possible to mitigate the later response by using a specific inhibitor of the MEK-ERK signalling pathway. Indeed, $\mathrm{A}_{\mathrm{L}}$ cells treated with a non-cytotoxic dose of PD 98059 showed suppression of COX-2 expression after ionising irradiation (Figure 4B). This result indicated that the MEK-ERK pathway may have a role in the COX-2 induction after cytoplasmic irradiation.

\section{DISCUSSION}

With the availability of a precision microbeam at Columbia University, we previously reported that irradiation of cellular cytoplasm with an exact number of $\alpha$-particles led to increased mutation yield, whereas inflicting minimal toxicity and that this process is mediated by free radicals. In this study, we used the microbeam setting and $A_{L}$ cell system to extend the study to provide further evidence that cytoplasmic irradiation leads to elevated levels of ROS and RNS. As only a limited number of cells can be irradiated per day, typically $<25000$, most of the analyses on cellular signalling can only be achieved using semi-quantitative immunostaining methods in this study.

DNA damage induced by ROS has been proposed as a key event relevant to mutagenesis and carcinogenesis. 8-Hydroxydeoxyguanosine

is one of the most abundant oxidised DNA bases and has been shown to be a mutagenic DNA lesion (Gajewski et al, 1990). Haegele et al (1998) reported that X-radiation induced a small but significant increase in 8-OHdG concentration in vivo in mammary gland DNA. High levels of 8-OHdG have been observed in normal human epidermis or purified DNA exposed to ultraviolet radiation (Wei et al, 1997). We showed here that cytoplasmic irradiation induced the generation of 8-OHdG in $A_{L}$ cells. Such an induction can be efficiently suppressed in the presence of DMSO. This result is consistent with the previous mutation data ( $\mathrm{Wu}$ et al, 1999), suggesting generation of free radicals cause oxidative stress in cytoplasmic irradiated cells. The RNS-mediated signalling can often be corroborated with signal transduction associated with oxygen-derived species (Narayanan et al, 1997). It has been demonstrated that nitric oxide synthase produces sustained high concentrations of NO in various mammalian cells after exposure to cytokines, hypoxia, heavy metals, crocidolite, and radiation (Chao et al, 1996; Zhuang et al, 1998; Matsumoto et al, 2001). In cytoplasmic-irradiated cells, 3-nitrotyrosine, a nitrosated protein product used as a marker of peroxynitrite anions, was significantly elevated. In addition, the incidence of mutation induced by cytoplasmic irradiation was dramatically inhibited by L-NMMA, implicating a critical role of RNS in the mutagenicity induced by cytoplasmic irradiation.

Consistent with the increase of oxidative stress, lipid peroxidation also increased significantly after transversal of $\alpha$-particles through the cytoplasm, which was evident by higher level of 4-HNE. Accumulating evidence in recent years has shown that 4-HNE can function as potential signalling molecules in various pathways (Chiarpotto et al, 1999; Kumagai et al, 2002; Lu et al, 2002; Burlando et al, 2003). Therefore, the enhanced production of 4 -HNE in cytoplasmic-irradiated cells is likely to induce downstream responses that lead to its mutagenic effect. Indeed, in addition to the induction of 4-HNE, we also detected increased COX-2 expression in the irradiated cells. Cyclooxygenase-2 is normally not present or present in very low amounts under basal conditions. However, it is promptly induced by various stimuli including proinflammatory cytokines such as IL-1 $\beta$ and TNF- $\alpha$, growth factors and tumour promoters (Uchida and Kumagai, 2003). There have been reports indicating that COX-2 expression may be associated with the accumulation of lipid peroxidation products. Within human atheromatous lesions, COX-2 was colocalised with 4-HNE in foamy macrophages, implicating that COX-2 expression is associated with the accumulation of lipid peroxidation products (Kumagai et al, 2004). 4-Hydroxynonenal was also found to be responsible for the induction of COX-2 in 3T3-L1 adipose cells under oxidative stress (Zarrouki et al, 2007). We further demonstrated that in cytoplasmic-irradiated $\mathrm{A}_{\mathrm{L}}$ cells, ERK activity was elevated and that pre-treatment with lipid peroxidation blocker BHT resulted in reduced ERK phosphorylation (Figure 4), implicating an upstream regulatory role of lipid peroxidation on ERK activation. Moreover, specific MEK1 inhibitor PD98059 was able to suppress COX-2 expression (Figure 4B), further suggesting the involvement of ERK in this event. The p38 kinase activity, however, did not seem to change after cytoplasmic irradiation (data not shown). This may possibly be because of the diverse response of p38 kinase to external stimuli (Zhou et al, 2005).

Previous studies in our laboratory have shown that COX-2 is critically linked to the radiation-related bystander effect in normal human lung fibroblasts and that the MAP kinase signalling cascade has an important role in this process (Zhou et al, 2005). Our results here provided further evidence to demonstrate that ROS and RNS are both involved in the cytoplasmic irradiation-induced genotoxicity. More importantly, our data suggest that a lipid peroxidation signalling pathway involving 4-HNE and COX-2 may have a critical role in the mutagenic effect induced by cytoplasmic irradiation. Given the similarities in cellular response 
and phenotype between cytoplasmic irradiation and bystander effect, these two phenomena are likely to share some signalling pathways. However, this pathway may only present one of the many pathways activated by irradiation because the induction of COX-2 could only partially be inhibited by lipid blocker BHT (Figure 3). Further studies on the cellular and molecular mechanisms of cytoplasmic irradiation will enable us to formulate a more accurate model in assessing the health effects of low dose ionising radiation.

\section{REFERENCES}

Burlando B, Magnelli V, Panfoli I, Berti E, Viarengo A (2003) Ligandindependent tyrosine kinase signalling in RTH 149 trout hepatoma cells: comparison among heavy metals and pro-oxidants. Cell Physiol Bioche 13: $147-154$

Burney S, Tamir S, Gal A, Tannenbaum SR (1997) A mechanistic analysis of nitric oxide-induced cellular toxicity. Nitric Oxide: Biol Chem 1: $130-144$

Chao C, Park S, Aust AE (1996) Participation of nitric oxide and iron in the oxidation of DNA in asbestos-treated human lung epithelial cells. Arch Biochem Biophys 326: $152-157$

Chiarpotto E, Domenicotti C, Paola D, Vitali A, Nitti M, Pronzato MA, Biasi F, Cottalasso D, Marinari UM, Dragonetti A, Cesaro P, Isidoro C, Poli G (1999) Regulation of rat hepatocyte protein kinase C beta isoenzymes by the lipid peroxidation product 4-hydroxy-2,3-nonenal: a signaling pathway to modulate vesicular transport of glycoproteins. Hepatology 29: $1565-1572$

Dent P, Yacoub A, Fisher PB, Hagan MP, Grant S (2003) MAPK pathways in radiation responses. Oncogene 22: 5885-5896

Devasagayam TP, Tilak JC, Boloor KK, Sane KS, Ghaskadbi SS, Lele RD (2004) Free radicals and antioxidants in human health: current status and future prospects. J Assoc Physicians India 52: 794-804

Dianzani MU, Barrera G, Parola M (1999) 4-Hydroxy-2, 3-nonenal as a signal for cell function and differentiation. Acta Biochim Pol 46: $61-75$

Dickinson DA, Iles KE, Watanabe N, Iwamoto T, Zhang H, Krzywanski DM, Forman HJ (2002) 4-hydroxynonenal induces glutamate cysteine ligase through JNK in HBE1 cells. Free Radic Biol Med 33: 974-987

Esterbauer H, Schaur RJ, Zollner H (1991) Chemistry and biochemistry of 4-hydroxynonenal, malonaldehyde and related aldehydes. Free Radic Biol Med 11: $81-128$

Floyd RA, Hensley K (2002) Oxidative stress in brain aging. Implications for therapeutics of neurodegenerative diseases. Neurobiol Aging 23: $795-807$

Gajewski E, Rao G, Nackerdien Z, Dizdaroglu M (1990) Modification of DNA bases in mammalian chromatin by radiation generated free radicals. Biochemistry 29: 7876-7782

Haegele AD, Wolfe P, Thompson HJ (1998) X-radiation induces 8-hydroxy$2^{\prime}$-deoxyguanosine formation in vivo in rat mammary gland DNA. Carcinogenesis 19: 1319-1321

Hei TK, Liu SX, Waldren CA (1998) Mutagenicity of arsenic in mammalian cells: role of reactive oxygen species. Proc Natl Acad Sci USA 95: 8103-8107

Hei TK, Wu LJ, Liu SX, Vannais D, Waldren CA, Randers-Pehrson G (1997) Mutagenic effects of a single and an exact number of alpha particles in mammalian cells. Proc Natl Acad Sci USA 94: 3765-3770

Hirst DG, Robson T (2007) Nitrosative stress in cancer therapy. Front Biosci 12: $3406-3418$

Kamiya H, Miura K, Ishikawa H, Inoe H, Nishimura S, Ohrsuka E (1992) C-Ha-ras containing 8-hydroxyguanine at codon 12 induces point mutations at modified and adjacent positions. Cancer Res 52: $3483-3485$

Kumagai T, Matsukawa N, Kaneko Y, Kusumi Y, Mitsumata M, Uchida K (2004) A lipid peroxidation-derived inflammatory mediator: identification of 4-hydroxy-2-nonenal as a potential inducer of cyclooxygenase-2 in macrophages. J Biol Chem 279: 48389-48396

Kumagai T, Nakamura Y, Osawa T, Uchida K (2002) Role of p38 mitogenactivated protein kinase in the 4-hydroxy-2-nonenal-induced cyclooxygenase-2 expression. Arch Biochem Biophys 397: 240-245

Leonarduzzi G, Scavazza A, Biasi F, Chiarpotto E, Camandola S, Vogel S, Dargel R, Poli G (1997) The lipid peroxidation end product 4-hydroxy-2,3-nonenal up-regulates transforming growth factor beta

\section{ACKNOWLEDGEMENTS}

The authors thank Dr Jarah Meador for critical reading of the paper, and Mr Kevin Hopkins for his editorial assistance. This research was supported by funding from the National Institutes of Health Grants P01-CA 49062, R01-ES12888, and the Environmental Center grant ES 09089. The Radiological Research Accelerator Facility is an NIH supported Resource Center through grants EB-002033 (NIBIB). expression in the macrophage lineage: a link between oxidative injury and fibrosclerosis. FASEB J 11: $851-857$

Little JB (2000) Radiation carcinogenesis. Carcinogenesis 21: $397-404$

Lu C, Chan SL, Fu W, Mattson MP (2002) The lipid peroxidation product 4-hydroxynonenal facilitates opening of voltage-dependent $\mathrm{Ca}^{2+}$ channels in neurons by increasing protein tyrosine phosphorylation. J Bio Chem 277: 24368-24375

Matsumoto H, Hayashi S, Hatashita M, Ohnishi K, Shioura H, Ohtsubo T, Kitai R, Ohnishi T, Kano E (2001) Induction of radioresistance by a nitric oxide-mediated bystancer effect. Radiat Res 155: 387-396

Morgan WF (2003) Is there a common mechanism underlying genomic instability, bystander effects and other nontargeted effects of exposure to ionizing radiation? Oncogene 22: 7094-7099

Narayanan PK, Goodwin EH, Lehnert BE (1997) Alpha particles initiate biological production of superoxide anions and hydrogen peroxide. Cancer Res 57: 3963-3971

Poli G, Albano E, Dianzani MU (1987) The role of lipid peroxidation in liver damage. Chem Phys Lipids 45: 117-142

Requena JR, Fu MX, Ahmed MU, Jenkins AJ, Lyons TJ, Thorpe SR (1996) Lipoxidation products as biomarkers of oxidative damage to proteins during lipid peroxidation reactions. Nephrol Dial Transplant 11(Suppl 5): 48-53

Takeuchi T, Morimoto K (1994) Crocidolite asbestos increased 8-hydroxydeoxyguanosine levels in cellular DNA of a human promyelocytic leukemia cell line, HL60. Carcinogenesis (Lond) 15: 635-639

Uchida K, Kumagai T (2003) 4-hydroxy-2-nonenal as a COX-2 inducer. Mol Asp Med 24: 214-218

Waldren CA, Jones C, Puck TT (1979) Measurement of mutagenesis in mammalian cells. Proc Natl Acad Sci USA 76: 1358-1362

Wei H, Cai Q, Rahn R, Zhang X (1997) Singlet oxygen involvement in ultraviolet $(254 \mathrm{~nm})$ radiation-induced formation of 8-hydroxy-deoxyguanosine in DNA. Free Radic Biol Med 23: 148-154

Wu LJ, Randers-Pehrson G, Xu A, Waldren CA, Geard CR, Yu Z, Hei TK (1999) Targeted cytoplasmic irradiation with alpha particles induces mutations in mammalian cells. Proc Natl Acad Sci USA 96: 4959-4964

Xu A, Wu LJ, Santella RM, Hei TK (1999) Role of oxyradicals in mutagenicity and DNA damage induced by crocidolite asbestos in mammalian cells. Cancer Res 59: 5922-5926

Yang Y, Sharma R, Sharma A, Awasthi S, Awasthi YC (2003) Lipid peroxidation and cell cycle signaling: 4-hydroxynonenal, a key molecule in stress mediated signaling. Acta Biochim Pol 50: 319-336

Zarrouki B, Soares AF, Guichardant M, Lagarde M, Géloën A (2007) The lipid peroxidation end-product 4-HNE induces COX-2 expression through p38MAPK activation in 3T3-L1 adipose cell. FEBS Let 581: 2394-2400

Zhang H, Dickinson DA, Liu RM, Forman HJ (2005) 4-Hydroxynonenal increases gamma-glutamyl transpeptidase gene expression through mitogen-activated protein kinase pathways. Free Radic Biol Med 38: 463-471

Zhou H, Ivanov VN, Gillespie J, Geard CR, Amundson SA, Brenner DJ, Yu Z, Lieberman HB, Hei TK (2005) Mechanism of radiation-induced bystander effect: role of the cyclooxygenase-2 signaling pathway. Proc Natl Acad Sci USA 102: $14641-14646$

Zhuang JC, Lin C, Lin D, Wogan GN (1998) Mutagenesis associated with nitric oxide production in macrophages. Proc Natl Acad Sci USA 95: $8286-8291$

(c) (i) (2) This work is licensed under the Creative Commons CY NC SA Attribution-NonCommercial-Share Alike 3.0 Unported License. To view a copy of this license, visit http://creativecommons.org/ licenses/by-nc-sa/3.0/ 